Research Article

\title{
Experimental Study on Parameters Affecting the Runout Range of Rockfall
}

\author{
Jie Hu, ${ }^{1}$ Shucai Li, ${ }^{1}$ Shaoshuai Shi $\mathbb{D}^{1,2}$ Liping Li $\mathbb{D},{ }^{1}$ Qian Zhang $\mathbb{D},{ }^{3}$ Hongliang Liu, ${ }^{1}$ \\ and Peng He ${ }^{1}$ \\ ${ }^{1}$ Geotechnical and Structural Engineering Research Center, Shandong University, Jinan 250061, China \\ ${ }^{2}$ State Key Laboratory for Geomechanics and Deep Underground Engineering, China University of Mining and Technology, \\ Xuzhou 221116, China \\ ${ }^{3}$ Key Laboratory of Structural Health Monitoring and Control, Shijiazhuang Tiedao University, Shijiazhuang 050043, China \\ Correspondence should be addressed to Shaoshuai Shi; shishaoshuai@sdu.edu.cn
}

Received 3 August 2017; Revised 4 December 2017; Accepted 26 December 2017; Published 22 March 2018

Academic Editor: Claudio Tamagnini

Copyright (C) 2018 Jie Hu et al. This is an open access article distributed under the Creative Commons Attribution License, which permits unrestricted use, distribution, and reproduction in any medium, provided the original work is properly cited.

\begin{abstract}
This paper presents the law of rockfall runout range and the effect on lateral dispersion caused by different parameters. A creative combined model test bench was developed as the test site, the slope, and blocks were artificial using similar materials that can meet the strength required in the experiment. As to the analysis of rockfall runout range, a series of experiments were carried out, and the shape, weight, and release heights of blocks were varied to clarify the effect of 3 factors. The motion trajectory of block was recorded based on a high-speed camera and a defined coordinate system. In addition, the final longitudinal and lateral runout distances of block were also measured. Furthermore, an extended laboratory investigation was conducted, consisting of 160 tests with cubical blocks, and an empirical model was proposed from the test results that estimates the lateral dispersion $W / L$ of cubical blocks with different mass and release height. For the design of practical mitigation measures, the research results in this paper may provide a useful reference.
\end{abstract}

\section{Introduction}

Rockfall represents a significant safety hazard to transportation in mountainous areas around the world. It is the cause of serious injuries or fatalities to personnel and can damage infrastructure. Moreover, it can result in major financial losses when transportation is temporarily stopped for safety reasons $[1,2]$. The hazard associated with rockfall events needs to be rigorously managed in these areas with poor environment. Therefore, the research on rockfall is of great significance for its forecast and mitigation. To illustrate the rockfall problem, Figure 1 shows a rockfall event which occurred in Sichuan Province on July 17, 2014. A total of 10 people have been dead in the accident, and more than 20 people were injured. The disaster cut off G213 road for 40 hours and caused direct financial losses more than 2,000,000 dollars.

During the rockfall movement and before impacting with slope, the block moves along a parabolic path under the action of gravity and initial velocity, and the trajectory can be calculated by kinematics formulas. Once the block contacts with a slope, the trajectory might change into another one, and the movement form becomes uncertain because of the kinematic and topographical conditions. Common response types to rebound include bouncing, rolling, and sliding or a combination thereof [3]. To reduce rockfall disaster, various mitigation measures including wire anchors, rock bolts, intercepting ditches, SNS flexible nets, and attenuator systems have been extensively adopted $[1,4,5]$. The design of these rockfall mitigations is based on the trajectory of rockfall movement including bounce height, runout distance, kinetic energy, and lateral dispersion. For simulation of the block's trajectory, the three parameters former can be achieved by using most 2-D numerical software such as RocFall [6] or CRSP [7]. As to the analysis of rockfall lateral dispersion, practitioners commonly adopt 3-D numerical simulation software and give recommended values to implement mitigation devices. 

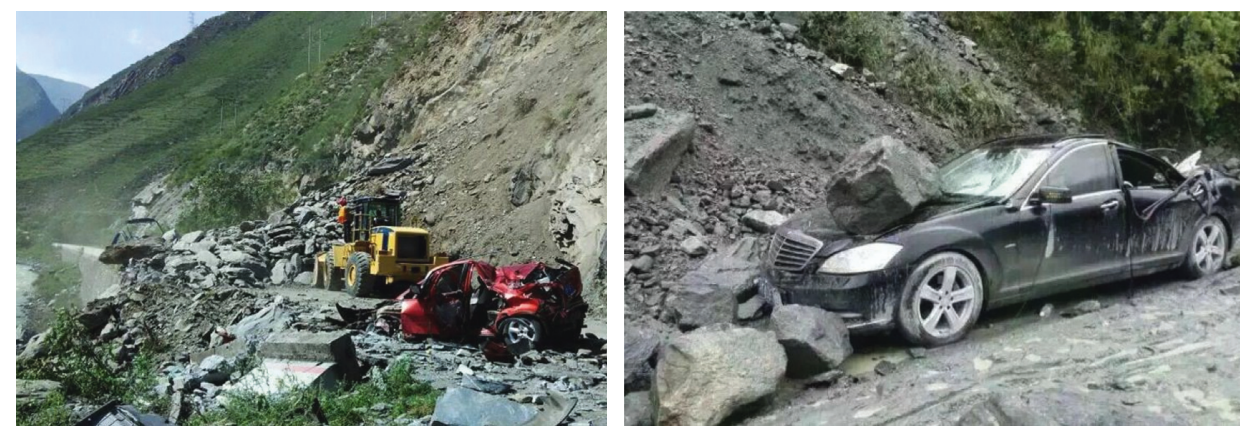

Figure 1: A rockfall disaster occurred in Sichuan Province in China.

However, the usage of the lump-mass model is common in these programs, where a block is described as rigid and dimensionless with an idealized shape $[8,9]$. In this model, the block's actual shape and configuration at impact are neglected, which affect the lateral dispersion result evidently. Hence, the law of rockfall lateral runout and the effect on dispersion caused by different parameters (such as shape) cannot be achieved by most numerical simulations [10].

At the slope scale, the most evident 3-D effect is the occurrence of "lateral dispersion." Lateral dispersion is defined as the ratio of the lateral runout distance from the slope central line $W$ (as seen looking at the face of the slope) to the runout distance $L$ from the toe of the slope measured in a straight line traced over the planar slope and onto the flat runout zone [11, 12]. Figure 2 shows the definition of lateral dispersion. Literature studies considering the determination of rockfall lateral runout have shown that the factors can be classified into three categories: macrotopographic factors, related to the overall morphology (such as slope gradient, concavity and convexity, and longitudinal and transversal ridges); microtopographic factors, controlled by the slope "roughness," which is a function of the grain-size distribution of slope debris affecting both the energy loss and geometrical scattering of trajectories during impact; and dynamic factors, relevant to interaction between slope features and block dynamics during bouncing, sliding, and rolling [1, 10, 11]. According to Azzoni and Freitas [11], the lateral runout distance of rockfall increases for long gentle slope, and lateral dispersion usually amounts to $20 \%$ regardless of length of the slope. Additionally, Agliardi and Crosta [1] produced lateral dispersion to be up to $34 \%$ on the basis of high-resolution numerical models performed on natural rough and geometrically complex slopes.

Many researches have been conducted to analyze the runout range and dispersion characteristic of rockfall, including field test, laboratory investigation, and numerical simulation. However, there has not been an experimental technique to comprehensively evaluate the dependence of lateral dispersion on different modelling parameters. In this study, a creative model test was presented to simulate the rockfall process and develop the law of lateral dispersion. Additionally, 420 groups of experiments on rockfall were conducted, and the shape, weight, and release height of blocks were varied to clarify the 3 factors on the dispersion. Furthermore, an extended laboratory investigation was

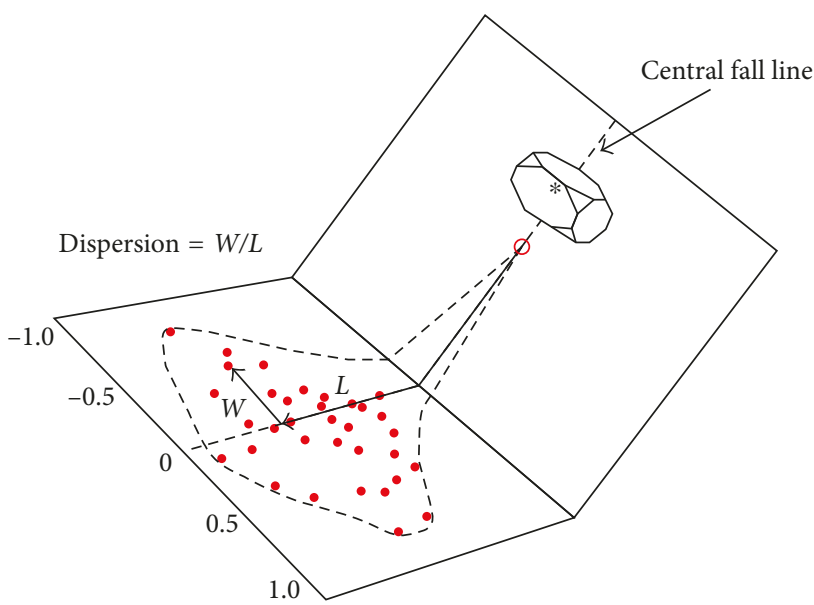

Figure 2: Definition of lateral dispersion (modified from [12]).

conducted, consisting of 160 tests with cubical blocks, and an empirical model was proposed from the test results that estimates the lateral dispersion $W / L$ of cubical blocks with different mass and release height.

\section{Laboratory Investigation}

The experimental design of this research was to isolate the roles of rock-shape, rock-mass, and rock-release height in rockfall runout dynamics from the large number of repeatable experiments. For laboratory study, large natural rockfall is impractical. Thus, the method which used physical model tests with small-sized rock blocks and artificial slope in combination with a release device and a recording system was applied. This approach facilitated repeatability and the quantification of rockfall dynamics with sufficient data to be examined statistically and characterize the behavior of different parameters during rockfall runout.

2.1. Experimental Apparatus. The model test system apparatus specifically built for this study was established including the steel structural frame, a rock-release device, the artificial slope, rock blocks, and a recording system (Figure 3 ). The structural frame was made of steel channels and connected by high-strength bolts to keep the stability of 


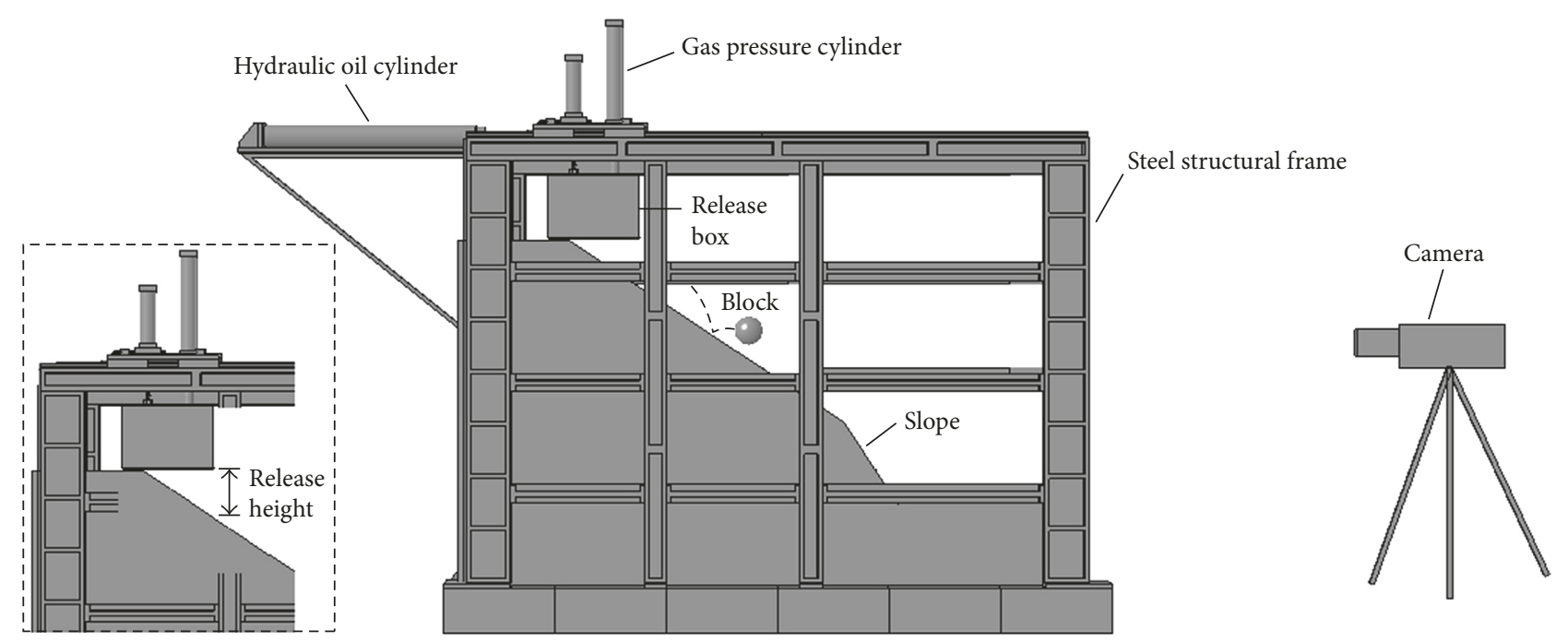

Figure 3: Experimental apparatus.

structure. In addition, the size of experimental bench can be adjusted conveniently according to the testing requirements by means of adding or reducing the number of single frames. To meet the requirement of releasing rock blocks at any position, the rock-release device was mainly composed of release box involving an inclined bottom with adjustable inclination, two types of gas pressure cylinder (one is for lifting and dropping box and the other one is for controlling inclination of box bottom), and also a hydraulic oil cylinder to adjust the longitudinal position of the rockrelease box.

Experiments were conducted with artificial slope made of material similar to phyllite that is composed of sand, water, barite powder, vaseline, silicone oil, cement, and talc powder according to the proportion developed by Zhang [13], and the detailed proportion is shown in Table 1. This similar material was developed based on the slope material in the actual engineering project. The homogeneity of such material is good, and the physical-chemical properties are stable. The unit weight is $25.1 \mathrm{kN} / \mathrm{m}^{3}$, which is close to that of original rock. The slope was cut into steeper at the toe to observe more obvious phenomenon for the first impact position of block with flat zone, and the slope surface was $1.5 \mathrm{~m}$ wide and $0.8 \mathrm{~m}$ high with $45^{\circ}$ slope angle. The material used to fabricate rock blocks by molds adopted the mixture of sand, barite powder, gypsum, cement, and water, which meets the requirement of high strength to prevent shattering during the collision. This allowed for the creation of numerous identical blocks cast from molds, resulting in cubical, spherical, and wedgy blocks with different mass. The properties of the materials used to fabricate slope and blocks are presented in Table 2. The colliding block was put on the bottom plate of release box and released towards the impact surface by controlling the bottom plate inclination. Tests were recorded by a high-speed video camera (Sony NEX-FS700) at a capture rate of $120 \mathrm{fps}$, allowing for rockfall trajectory acquisition and analysis of the block's movement influenced by several parameters. The camera was placed at a distance of $1.5 \mathrm{~m}$ from the test bench and faced the slope.
2.2. Experimental Program. As data were acquired in the laboratory test, the falling blocks were varied relative to cubical, spherical, and wedgy blocks with different mass. As the response to impact of block is highly variable, many repetitions were performed for each test set. In total, 420 laboratory tests were performed, the details of which are given in Table 3, and each case was tested with 60 times to account for the randomness of the impact. For each test, the angle of slope was adopted as $45^{\circ}$ and the releasing angle was taken as $30^{\circ}$. The soil slope profile was regularized after each impact to ensure the reproducibility of the tests. The effect of shape was investigated by comparing cubical, spherical, and wedgy blocks with same initial conditions (Table 3-sets 1, 3, and 6). The effect of block mass was examined by releasing cubical blocks on slope surface with two different mass values (Table 3-sets 3 and 5). For effect of block release height, tests were performed by controlling the vertical distance between block and slope surface at initial position from $10 \mathrm{~cm}$ to $20 \mathrm{~cm}$ (Table 3-sets 1-2, 3-4, and 6-7). The test results were examined in a statistical manner providing a quantification of characteristic rockfall behavior according to several parameters. It is necessary to build a suitable coordinate system to record the impact position of block (Figure 4). The direction away from the slope was defined as " $-y$ " in this experiment to keep the coordinate system same among different experiments using this model test system. In the later experiment, a model tunnel will be excavated at the toe of slope, and the excavation direction $(y)$ will be defined as positive direction.

2.3. Experimental Procedure. For each test, 10 blocks with same shape and mass were put into release box. According to the design of each test set, release box was moved to the mid line of the slope ( $x=0$, refer to the coordinate system shown in Figure 4), and two gas pressure cylinders were controlled by computer to adjust the height between release box and slope surface and the inclination angle of box bottom, respectively. In order to capture the block trajectory and analyze the effect 
TABLE 1: Composition and proportion (based on mass) of similar materials for phyllite.

\begin{tabular}{lccccccc}
\hline Composition & Sand & Barite powder & Silicone oil & Vaseline & Water & Cement & Talc powder \\
\hline Proportion (\%) & 62 & 6 & 6 & 6 & 8 & 2 & 10 \\
\hline
\end{tabular}

TABLE 2: Properties of materials simulating slope and block.

\begin{tabular}{lcc}
\hline & Slope & Block \\
\hline Unit weight $\left(\mathrm{kN} / \mathrm{m}^{3}\right)$ & 25.1 & 26.5 \\
Elastic modulus $(\mathrm{GPa})$ & 0.06 & 0.37 \\
Poisson's ratio & 0.3 & 0.23 \\
Uniaxial strength $(\mathrm{MPa})$ & 0.41 & 0.72 \\
Cohesion $(\mathrm{MPa})$ & 0.16 & 0.27 \\
Internal friction angle $\left(^{\circ}\right)$ & 34.4 & 34.1 \\
\hline
\end{tabular}

TABLE 3: Details of experimental program.

\begin{tabular}{|c|c|c|c|c|}
\hline Set & Block shape & $\begin{array}{c}\text { Block } \\
\text { dimension } \\
(\mathrm{cm})\end{array}$ & $\begin{array}{c}\text { Block } \\
\text { mass (g) }\end{array}$ & $\begin{array}{c}\text { Release } \\
\text { height }(\mathrm{cm})\end{array}$ \\
\hline $\begin{array}{l}1 \\
2\end{array}$ & & $r=2$ & $\begin{array}{l}72 \\
72\end{array}$ & $\begin{array}{l}10 \\
20\end{array}$ \\
\hline $\begin{array}{l}3 \\
4 \\
5\end{array}$ & & $\begin{array}{l}a=3 \\
a=4\end{array}$ & $\begin{array}{c}72 \\
72 \\
170\end{array}$ & $\begin{array}{l}10 \\
20 \\
10\end{array}$ \\
\hline $\begin{array}{l}6 \\
7\end{array}$ & & $b=6$ & $\begin{array}{l}72 \\
72\end{array}$ & $\begin{array}{l}10 \\
20\end{array}$ \\
\hline
\end{tabular}

Exegesis: these blocks were fabricated as regular geometric solids; the block dimensions and block mass were approximate values considering error in the fabrication process; " $r$ " means radius of spherical block; " $a$ " means edge length of cubical block; " $b$ " means edge length of wedgy block. Release height is defined as the vertical distance between block and slope surface at initial position.

of aforesaid parameters, the motion process was recorded by a camera. The video recorded can be replayed frame by frame in the computer system to obtain the position corresponding to the time accurately. Figure 5 shows the typical trajectory reconstruction composited by a series of pictures extracted from the video. The impact positions of blocks were recorded referring to the defined coordinate system when blocks impact the flat zone. The results are presented in Section 3 with an emphasis on the runout range of the falling blocks due to impact.

\section{Experimental Results and Evaluation}

3.1. Effect of Shape. The effect of shape was examined using spherical, wedgy, and cubical blocks with same mass of $72 \mathrm{~g}$, which were released at the height of $10 \mathrm{~cm} .60$ repetitions were performed for each shape, resulting in a total of 180 tests, and the mapped deposition data are presented in Figure 6 . The left axis of scatter diagram is ordinate $y$ and the axis below is abscissa $x$; the positive direction of $y$-axis is facing slope surface and the positive direction of $x$-axis is right. It is apparent that the spherical block shows greater

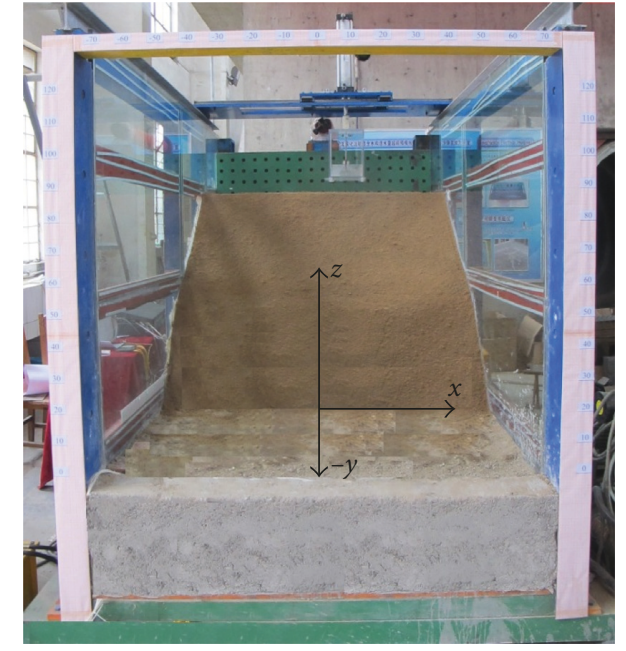

FIGURE 4: Defined coordinate system.

runout distance and less lateral dispersion than the cubical and wedgy blocks observed from the runout deposition patterns. The spherical block has the greatest runout distance with the absolute maximum of $27 \mathrm{~cm}$. However, the trend of the spherical block's lateral dispersion is not evident and shows considerably shorter lateral runout distances with overall maximums up to $10 \mathrm{~cm}$. During motion process, the spherical block was mainly in the state of rolling and with a greater velocity. Observed from the experimental phenomenon, the spherical block caused a little larger deformation of slope compared to other two shape types during collision process. The runout range of cubical block was apparently larger than that of the spherical block with lateral runout distance up to $40 \mathrm{~cm}$. Compared to the spherical block, the cubical block has larger frictional resistance when moving on the slope surface, and the collision configuration play an important role in rebound $[11,14]$. The spherical block's impact with the same configuration due to the shape's symmetry and cubical blocks may impact the surface with a side, edge, or corner, resulting in less runout distance and variation of lateral dispersion. For the wedgy block, the lateral runout distance is similar to the cubical block, but it has less runout distance than the other two shape types. Due to the dissymmetry, the initial release state affects the wedgy block's motion apparently which means changes in block release state may result in different edges and facets impacting the slope. From the observation of trajectory video recorded by camera, the block presents sliding state when the major facet contacts with slope surface and runouts less distance and dispersion. In contrast, the rebound phenomenon and trajectory changes are evident when the edges impact the slope related to larger coefficients of restitution of wedgy block [15]. Since the focus of the paper is on the lateral runout, only the statistical analysis referred to the $x$-axis is 


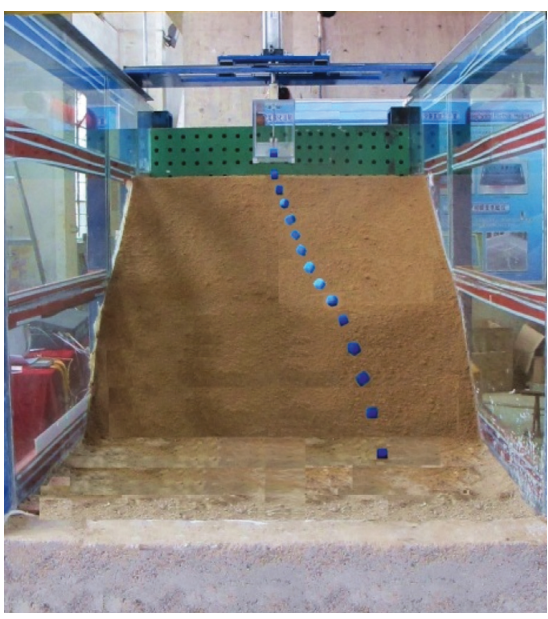

(a)

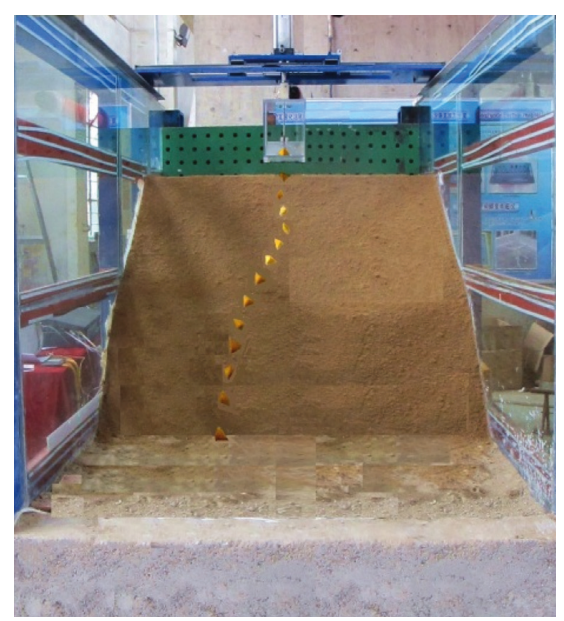

(b)

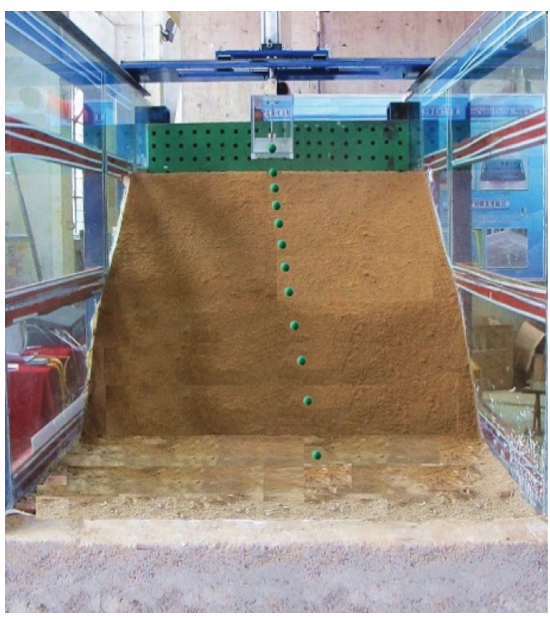

(c)

Figure 5: Trajectory reconstruction: a time-lapse image of the recorded trajectory. (a) Cubical block. (b) Wedgy block. (c) Spherical block.

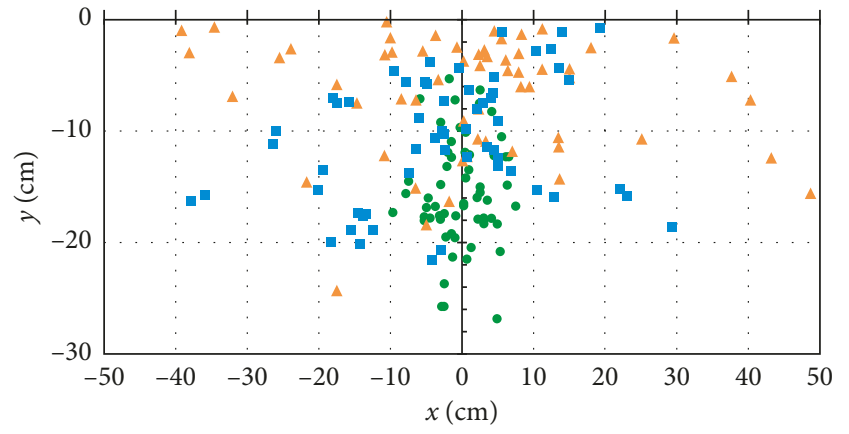

- Spherical block

$\triangle$ Wedgy block

- Cubical block

FIGURE 6: Impact position map of blocks corresponding to three shapes.

presented. Figure 7 shows the impact position's lateral coordinate $(x)$ distribution of three shape types in a statistical manner.

It can be concluded from Figure 7 that deviation regularity appeared to be approximately normal distribution by qualitative visual agreement. The contact mode between the block and slope has a random effect on the block motion during the experimental procedure, which may explain the deviation regularity [10]. The evident statistics can be derived from the normal distributions that a spherical block has about $80 \%$ possibility of exhibiting a lateral runout distance less than $5 \mathrm{~cm}$ while the possibility of a cubical block locating in this range only for $50 \%$. The impact range of cubical and wedgy block is $67.2 \mathrm{~cm}$ and $87.9 \mathrm{~cm}$, respectively, which exceed the range of spherical block apparently. The detailed statistics of rockfall impact coordinate were listed in Table 4. For this regularity, the usage of the lump-mass model, where idealized spherical shape is common, to simulate runout range in $2 \mathrm{D}$ or $3 \mathrm{D}$ rockfall analysis methodology may ignore the crucial parameter (block shape types) for the design of mitigation.
3.2. Effect of Release Height. To study the effect of block's release height on the runout range, the height of release box was set to $10 \mathrm{~cm}$ and $20 \mathrm{~cm}$, respectively. Tests were performed with the three shape types of blocks; 60 repetitions were conducted for each set. The mapped deposition data of each shape with two different release heights are shown in Figure 8. For spherical and cubical block, the runout distance evidently increases in the set of $20 \mathrm{~cm}$ release height compared to $10 \mathrm{~cm}$ due to larger initial velocity when firstly contacts with slope surface. The spherical block has larger lateral runout range when release height is $20 \mathrm{~cm}$, and the distribution of $x$ coordinate is mainly located in the range of $-15 \mathrm{~cm}$ to $15 \mathrm{~cm}$, which is still the least lateral dispersion among three shape types. As to the cubical block, it is apparent that the runout distance and lateral dispersion increase from release height $10 \mathrm{~cm}$ to $20 \mathrm{~cm}$, and the greatest runout distance and lateral runout distance can access to $40 \mathrm{~cm}$ and $50 \mathrm{~cm}$, respectively. Observed from the video recorded during motion process, the cubical block has more evident rebound phenomenon, and the change possibility of postimpact trajectory has a trend of increase. However, the regularity is not evident for wedgy block and the runout range is similar in two release states, which can pose a recognition that the effect of height of wedgy dangerous rock (Figure 9) can be ignored when designing the mitigation.

3.3. Effect of Block Mass. To address the effect of block mass on the runout range, the height of release box was set to $10 \mathrm{~cm}$; 120 tests were performed with the cubical blocks, as they more realistically represent the contact configurations of natural rockfalls. The mapped deposition data of two block types with different mass $(72 \mathrm{~g}, 170 \mathrm{~g})$ are shown in Figure 10. By looking at the plot, it is apparent that the heavier block shows greater runout distance with the absolute maximum of $28 \mathrm{~cm}$, whereas the lateral runout range has the trend of decrease from block mass $72 \mathrm{~g}$ to $170 \mathrm{~g}$ and the distribution of $x$ coordinate is mainly located in the 


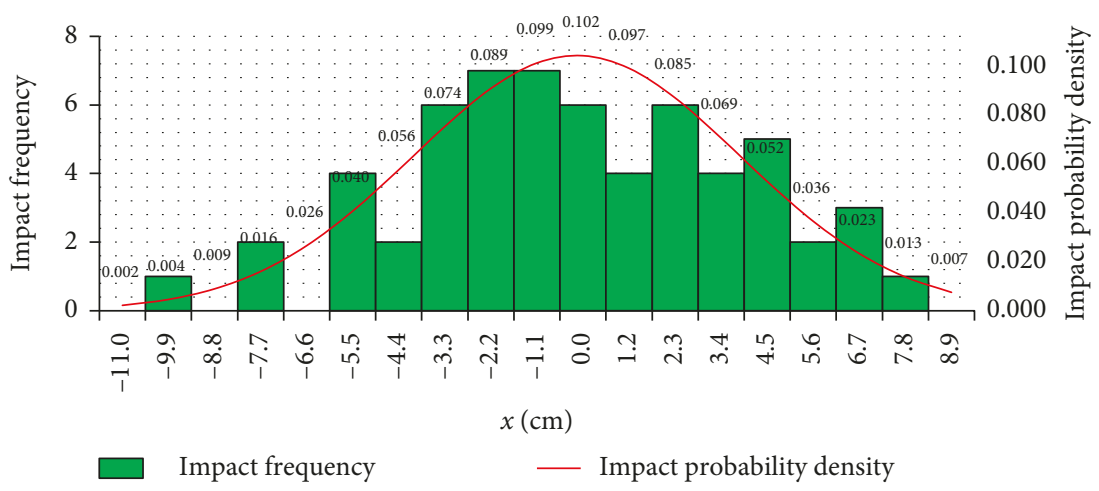

(a)

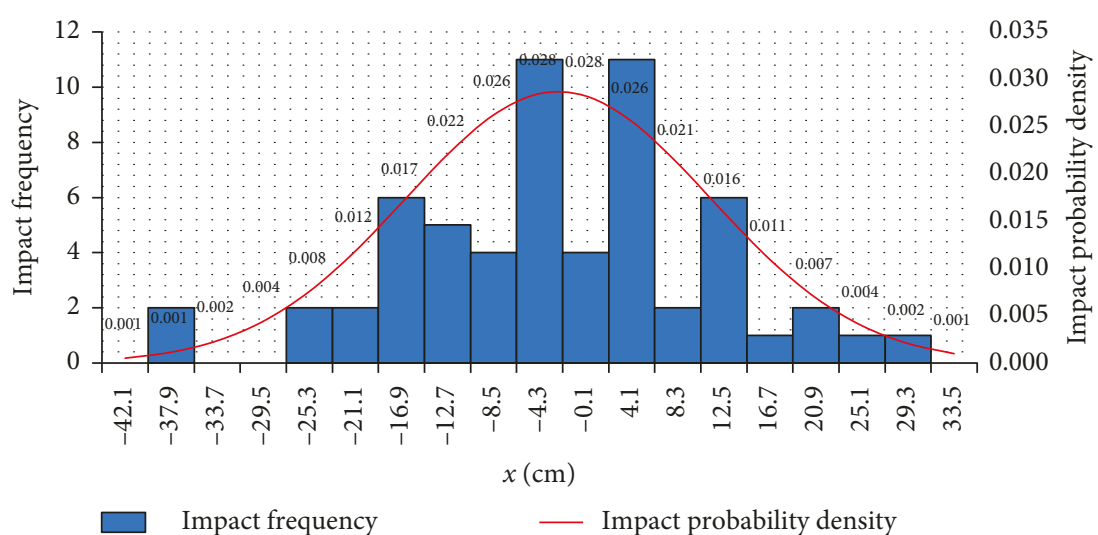

(b)

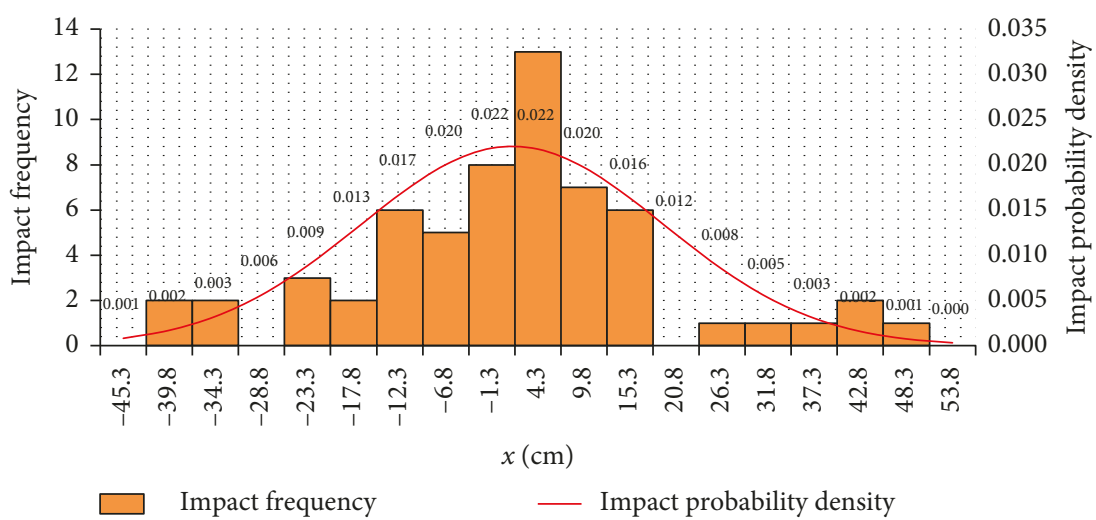

(c)

Figure 7: Impact frequency and probability of $x$ range. (a) Spherical block. (b) Cubical block. (c) Wedgy block.

TABLE 4: Statistics of rockfall impact coordinate ( $x$-axis).

\begin{tabular}{lccc}
\hline Parameter & $\begin{array}{c}\text { Spherical } \\
\text { block }\end{array}$ & $\begin{array}{c}\text { Cubical } \\
\text { block }\end{array}$ & $\begin{array}{c}\text { Wedgy } \\
\text { block }\end{array}$ \\
\hline Maximum value & 7.5 & 29.3 & 48.7 \\
Minimum value & -9.7 & -37.9 & -39.2 \\
Range & 17.2 & 67.2 & 87.9 \\
Mean value & -0.1 & -2.6 & 1.2 \\
Standard & 3.9 & 13.9 & 18.1 \\
deviation & & & \\
\hline
\end{tabular}

range of $-15 \mathrm{~cm}$ to $15 \mathrm{~cm}$. The plot provides the regularity that the lighter block may cause more serious threat to mitigation measures in the lateral dimension which is important to the design of protective structures (e.g., SNS flexible nets and rockfall barrier wall).

3.4. Analysis of Dispersion Ratio $W / L$. The dispersion ratio defined as $W / L$ has been selected as descriptor of the lateral dispersion occurring during the rockfall. It is important to consider the dispersion ratio because they are responsible for defining the extent of the rockfall runout zone [16]. By quantifying the lateral runout, the tendency for a particular rock to follow the central fall line, or deviate from it, can be investigated. As to a specific slope, the volume and location of dangerous rock could be considered apparently 


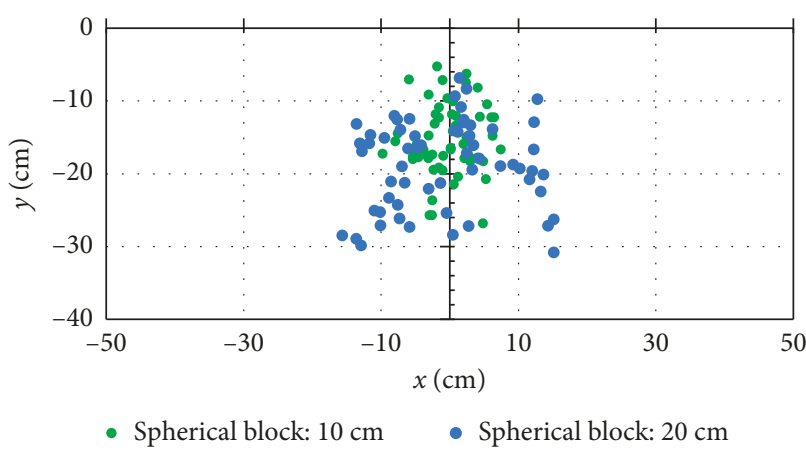

(a)

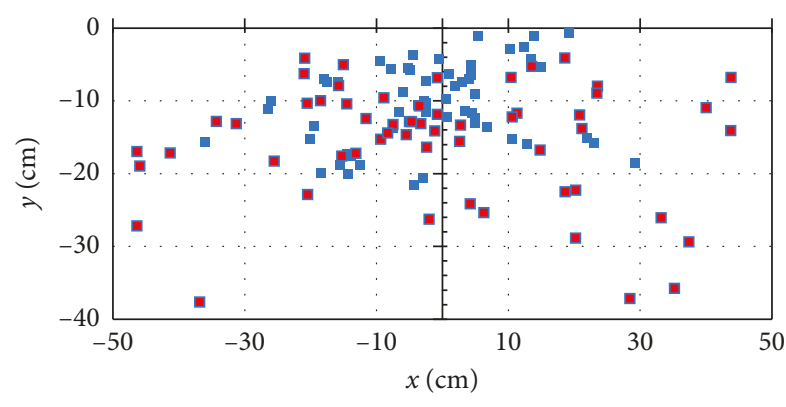

- Cubical block: $10 \mathrm{~cm}$
- Cubical block: $20 \mathrm{~cm}$

(b)

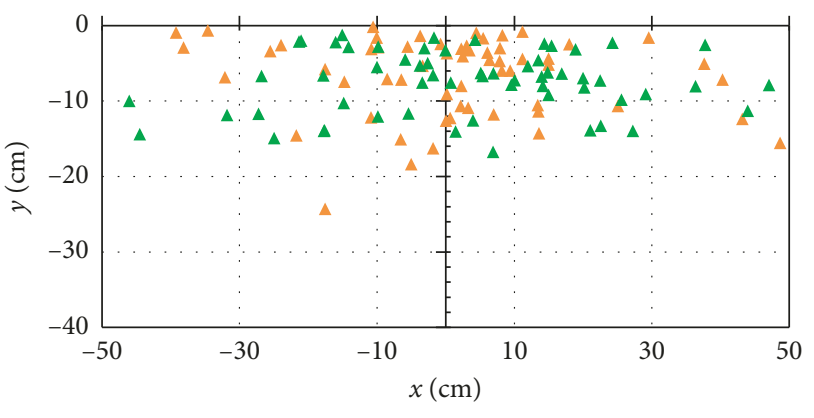

$\triangle$ Wedgy block: $10 \mathrm{~cm}$ \Wedgy block: $20 \mathrm{~cm}$

(c)

FIGURE 8: Impact position maps showing tests data comparison between two release heights $(10 \mathrm{~cm}, 20 \mathrm{~cm})$ for three shape types. (a) Spherical block. (b) Cubical block. (c) Wedgy block.

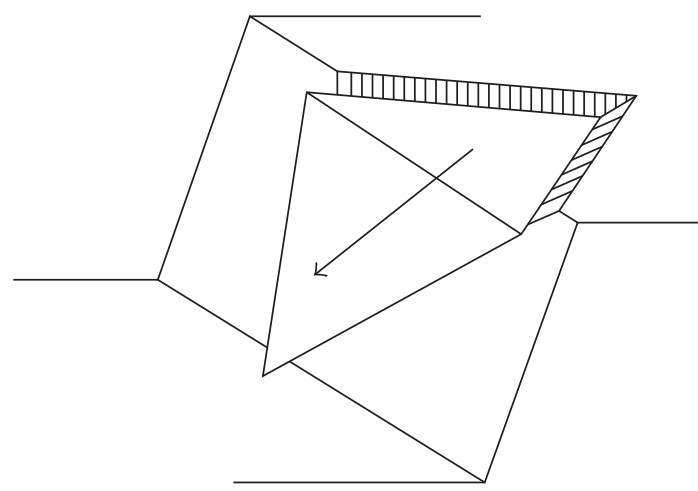

FIGURE 9: Schematic plot of potential wedgy block.

influencing the lateral runout, which also can be discovered from Sections 3.2 and 3.3. To quantify this intuitive expectation, an extended experimental procedure was implemented. The inclination of release box bottom was set as $30^{\circ}$, and four test sets were performed with the release heights of $5 \mathrm{~cm}, 10 \mathrm{~cm}, 15 \mathrm{~cm}$, and $20 \mathrm{~cm}$ for each mass $(72 \mathrm{~g}, 170 \mathrm{~g}$ ); a total number of 160 tests has been conducted. The length of slope is equivalent to $1.1 \mathrm{~m}$, and the $W / L$ value of each test set was calculated.

Figure 11(a) depicts the results in terms of difference in release height ( $x$-axis) and dispersion ratio $W / L$ ( $y$-axis), where all measurements are presented. It is apparent that as the difference in release height increases, $W / L$ value

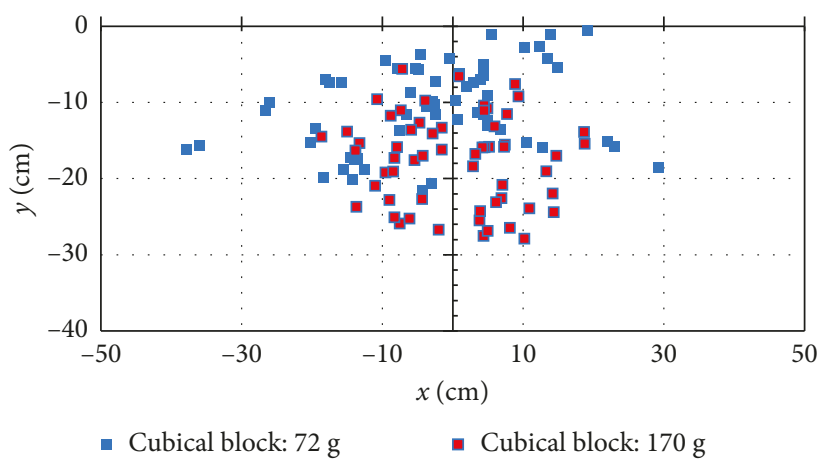

Figure 10: Impact position maps showing test data comparison between two block mass values $(72 \mathrm{~g}, 170 \mathrm{~g})$ for cubical block.

increases. Additionally, the magnitude of dispersion ratio is affected by the block mass, and the lighter block has greater $W / L$ value specifically. This is especially apparent in Figure 11(b), where the 5th and 95th percentile values of each test set are plotted as the mean values of $W / L$ cannot describe the postimpact trajectory reasonably. An empirical model to consider dispersion is derived from the experimental results; the 5th percentile boundary can be best represented by a linear function and the 95th percentile boundary by an exponential referred to [10]. Therefore, by performing least square regressions, the coefficients a, $b$, and $c$ (Figure 11(b)) of each boundary can be determined. In addition, the block with lighter mass has a larger distribution range of 


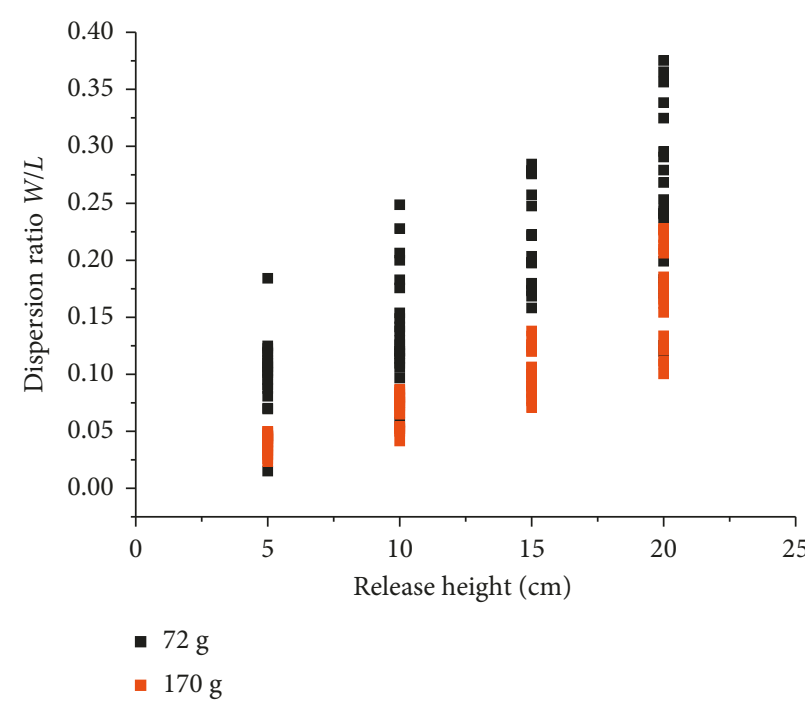

(a)

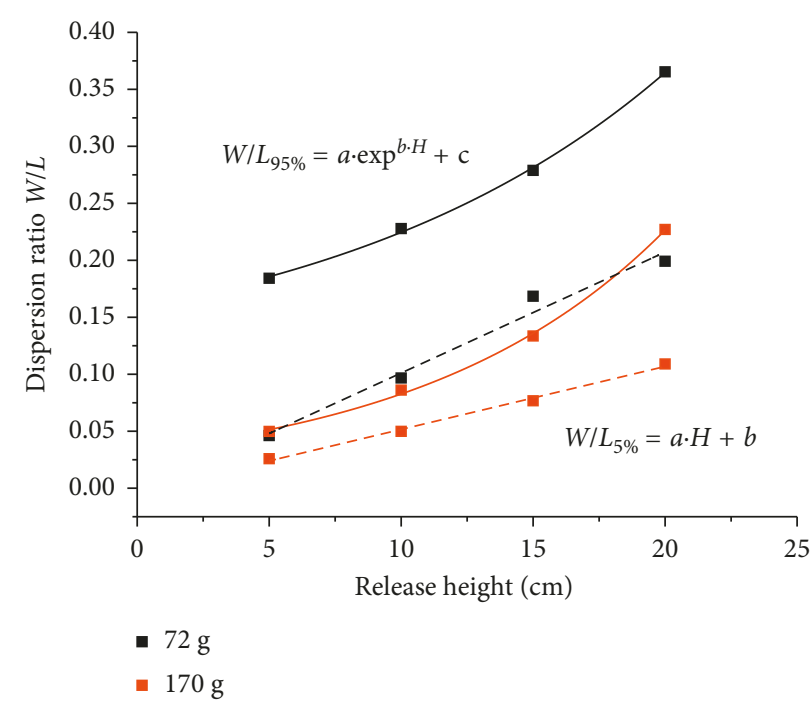

(b)

FIGURE 11: Dispersion ratio value as a function of difference in block mass and release height. (a) All values. (b) Formula fitting for 5th and 95th percentile values of each test set.

dispersion ratio observed from the plot. The fitting formulas in Figure 11(b) are given from (1-4). Equations (1) and (2) are fitted for the $72 \mathrm{~g}$ block. Equations (3) and (4) are fitted for the $170 \mathrm{~g}$ block.

$$
\begin{aligned}
& \left(\frac{W}{L}\right)_{95 \%}=0.0635 e^{H / 13.8675}+0.0953, \\
& \left(\frac{W}{L}\right)_{5 \%}=0.0104 H-0.001, \\
& \left(\frac{W}{L}\right)_{95 \%}=0.0314 e^{H / 10.0556}-0.0032, \\
& \left(\frac{W}{L}\right)_{5 \%}=0.0055 H-0.0036 .
\end{aligned}
$$

\section{Conclusions}

Rockfall trajectory modelling is a well-concerned question by many scholars and engineers to reduce the risk of potential rockfall disaster. However, there are numerous factors causing the uncertainty of block motion such as slope gradient, roughness of slope surface, characteristic of rock block, and some other dynamic factors. In particular, the response of block to impact with the slope surface and the trajectory change are affected by many parameters. In the past study, researchers mainly focused on the coefficients of restitution which is a key parameter to determine the travel distance, height of block, and energy variation simulated by computer program. Whereas the design of mitigation measures is not only based on the longitudinal distance and impact height, the lateral size of mitigation measures also relate to the lateral dispersion of rockfall. However, the deviation of rockfall trajectory is commonly neglected.

In the present study, a combined model test bench was specifically developed as the test site. The slope and blocks were artificial using similar materials, and the physical and mechanics parameters were tested in laboratory to meet the strength requirement in the experiment. To study the real-time trajectory of the blocks when moving on the slope surface, a video data acquisition methodology based on high-speed camera and defined coordinate system was adopted. In addition, a series of repeated experiments were conducted according to designed test sets clarifying the effect of block mass, block shape, release height on rockfall runout range and lateral dispersion.

The effect of shape was examined by performing tests with spherical, cubical, and wedgy blocks. Spherical blocks presented less lateral deviation and greater runout distance compared to cubical and wedgy blocks. In contrast to wedgy block, the cubical block has a greater runout distance and similar lateral distribution range. The difference in the scatter plot is attributed to the contact configuration of the blocks. The spherical block impacts in a repeatable manner while the cubical and wedgy blocks have numerous different configurations, which may affect the deviation in trajectory caused by impact. In addition, the runout range of wedgy block is also influenced by initial release state due to the dissymmetry and the difference of release state may result in different edges and facets impacting the slope, which affects the motion trajectory and final impact position apparently.

Release height also affects the runout range of block. As to the spherical and cubical block, the runout distance evidently increases from release height of $10 \mathrm{~cm}$ to $20 \mathrm{~cm}$, and the lateral runout range has a tendency to increase. But, the runout range of wedgy block was found to be insensitive to release height. The runout range is affected by block mass as well, and the effect of mass was studied by performing tests with the cubical 
block. From the results, it is apparent that the heavier block shows greater runout distance while the lateral runout range has the trend to decrease. Based on the results of extensive laboratory experiments, an empirical model was proposed in this paper, which could provide the trends of the main quantities involved in the problem of rockfall dispersion.

\section{Conflicts of Interest}

The authors declare that they have no conflicts of interest.

\section{Acknowledgments}

Much of the work presented in this article was supported by the National Natural Science Foundation of China (Grant no. 51609129 and 51609138), State Key Laboratory for GeoMechanics and Deep Underground Engineering, China University of Mining and Technology (Grant no. SKLGDUEK1515), Shandong Provincial Natural Science Foundation, China (Grant no. ZR2014EEQ002), Fundamental Research Funds of Shandong University (Grant no. 2015GN029) and Shandong Postdoctoral Innovation Project Special Foundation (Grant no. 201502025). The model tests were performed at the Geotechnical and Structural Engineering Research Center of Shandong University, and the help is highly appreciated.

\section{References}

[1] F. Agliardi and G. Crosta, "High resolution three-dimensional numerical modelling of rockfalls," International Journal of Rock Mechanics and Mining Sciences, vol. 40, no. 4, pp. 455-471, 2003.

[2] L. K. A. Dorren, "A review of rockfall mechanics and modelling approaches," Progress in Physical Geography, vol. 27, no. 1, pp. 69-87, 2003.

[3] O. Hungr, S. G. Evans, M. J. Bovis, and J. N. Hutchinson, "A review of the classification of landslides of the flow type," Environmental and Engineering Geoscience, vol. 7, no. 3, pp. 221-238, 2001.

[4] P. Bertolo, C. Oggeri, and D. Peila, "Full-scale testing of draped nets for rock fall protection," Canadian Geotechnical Journal, vol. 46, no. 3, pp. 306-317, 2009.

[5] G. Gottardi and L. Govoni, "Full-scale modelling of falling rock protection barriers," Rock Mechanics and Rock Engineering, vol. 43, no. 3, pp. 261-274, 2010.

[6] C. L. Jones, J. D. Higgins, and R. D. Andrew, Rockfall Simulation Program Version 4.0 Colorado Department of Transportation, Colorado Geological Survey, p. 127, 2000.

[7] L. R. Alejano, B. Pons, F. G. Bastante, E. Alonso, and H. W. Stockhausen, "Slope geometry design as a means for controlling rockfalls in quarries," International Journal of Rock Mechanics and Mining Sciences, vol. 44, no. 6, pp. 903-921, 2007.

[8] F. Guzzetti, A. Carrara, M. Cardinali, and P. Reichenbach, "Landslide hazard evaluation: a review of current techniques and their application in a multi-scale study, Central Italy," Geomorphology, vol. 31, no. 1-4, pp. 181-216, 1999.

[9] F. Guzzetti, G. Crosta, R. Detti, and F. Agliardi, "STONE: a computer program for the three dimensional simulation of rock-falls," Computers and Geosciences, vol. 28, no. 9, pp. 1079-1093, 2002.
[10] A. Pavlos and T. George, "Empirical model for predicting rockfall trajectory direction," Rock Mechanics and Rock Engineering, vol. 49, no. 3, pp. 927-941, 2016.

[11] A. Azzoni and M. H. Freitas, "Experimentally gained parameters, decisive for rock fall analysis," Rock Mechanics and Rock Engineering, vol. 28, no. 2, pp. 111-124, 1995.

[12] J. Glover and H. Michael, Rock-shape and its role in rockfall dynamics, Ph.D. thesis, Durham University, Durham, UK, 2015.

[13] Q. Zhang, Instability mechanism and control measures of bedding steep slope in high intensity seismic area, Ph.D. thesis, Shandong University, Jinan, China, 2015.

[14] S. Vijayakumar, T. Yacoub, and M. Ranjram, "Effect of rockfall shape on normal coefficient of restitution," in Proceedings of the 46th US Rock Mechanics/Geomechanics Symposium, Chicago, IL, USA, June 2012.

[15] R. H. Wong, K. W. Ho, and K. T. Chau, "Shape and mechanical properties of slope material effects on the coefficient of restitution on rockfall study," in Proceedings of the 4th North American Rock Mechanics Symposium NARMS 2000, pp. 507-514, Seattle, WA, USA, July 2000.

[16] C. M. Bunce, D. M. Cruden, and N. R. Morgenstern, "Assessment of the hazard from rockfall on a highway," Canadian Geotechnical Journal, vol. 34, no. 3, pp. 344-356, 1997. 


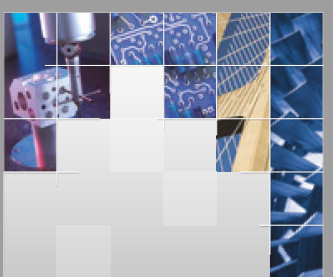

\section{Enfincering}
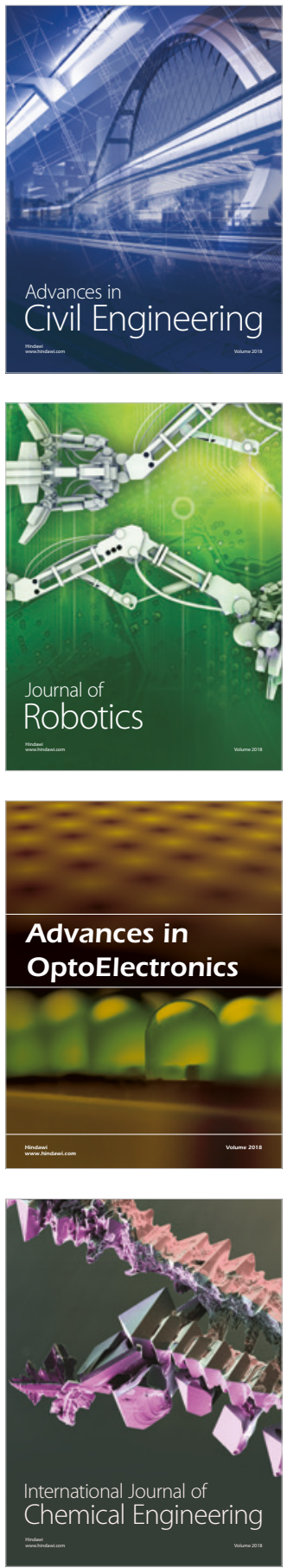

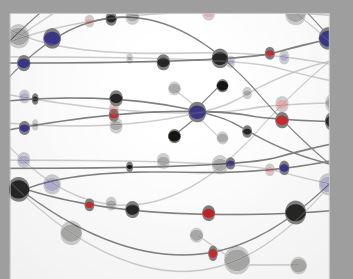

\section{Rotating \\ Machinery}

The Scientific World Journal

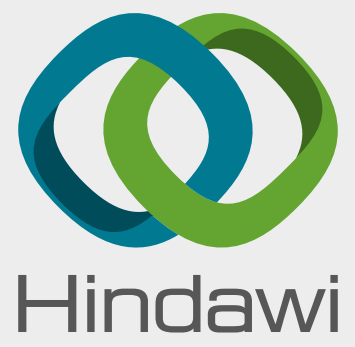

Submit your manuscripts at

www.hindawi.com
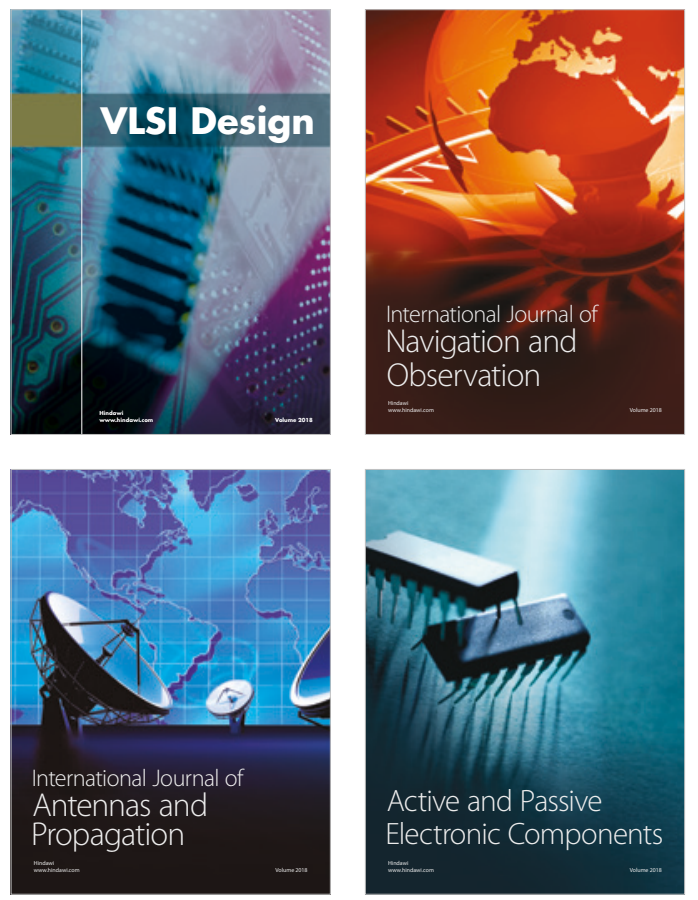
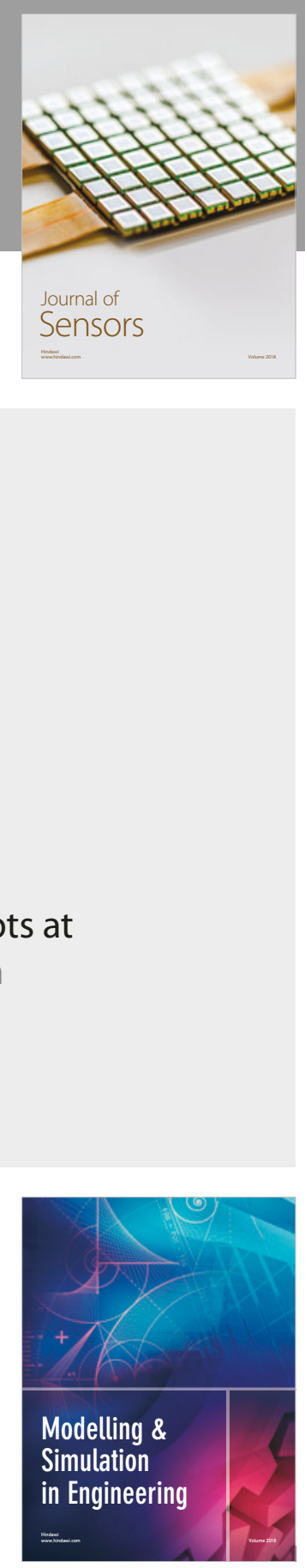

\section{Advances \\ Multimedia}
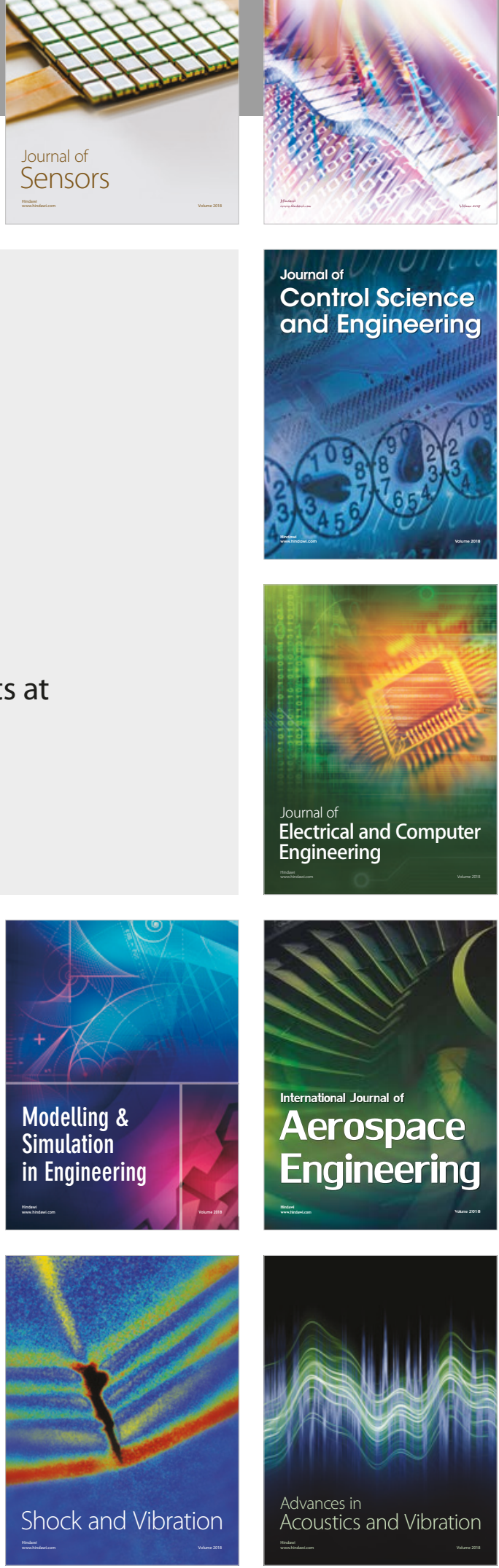